\title{
Tamanho de amostra de caracteres em híbridos de mamoneira
}

\author{
Sample size of the characters in castor bean
}

\author{
Alberto Cargnelutti Filho'* ${ }^{\text {I* }}$ Sinei José Lopes ${ }^{\mathrm{I}}$ Betânia Brum ${ }^{\mathrm{II}}$ Tatiani Reis da Silveira ${ }^{\mathrm{II}}$ \\ Marcos Toebe ${ }^{\mathrm{III}}$ Lindolfo Storck ${ }^{\mathrm{I}}$
}

\section{RESUMO}

O objetivo deste trabalho foi estimar o tamanho de amostra para avaliar caracteres de híbridos de mamoneira e verificar a variabilidade do tamanho de amostra entre híbridos e caracteres. Foram avaliadas 41 e 55 plantas dos híbridos Sara e Lyra, respectivamente, quanto aos caracteres de semente, de plântula, de planta adulta e de produção em Santa Maria, Estado do Rio Grande do Sul (latitude $29^{\circ} 42^{\prime}$ 'S, longitude 5349’W e 95m de altitude), no ano agrícola de 2007/2008. O tamanho de amostra apresenta variabilidade entre os híbridos Sara e Lyra para os seguintes caracteres: largura da semente, comprimento do epicótilo aos 14 dias após a emergência, graus-dia para emissão da primeira folha verdadeira, altura de planta no início do florescimento, altura de inserção do primeiro rácemo, número de inflorescências, número de rácemos por planta e número de cápsulas por rácemo. Há aumento do tamanho de amostra (número de plantas) para estimar caracteres de semente, de plântula, de planta adulta $e$ de produção, nessa ordem.

Palavras-chave: Ricinus communis L., planejamento experimental, dimensionamento de amostra, precisão experimental.

\section{ABSTRACT}

The aim of this research was to determine the sample size of the characters of hybrids in castor bean and to verify its variability among hybrids and characters. It was evaluated 41 plants and 55 hybrids (Sara and Lyra), respectively, regarding to the seed characters, adult plant seedling and production in Santa Maria, Rio Grande do Sul

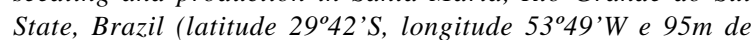
altitude), in the agriculture years of 2007/2008. It was found variability in the sample size among hybrids (Sara e Lyra) in relation to width of the seed, length of epicotyl 14 days after emergence, degree-days for issuance of the first true leaf, plant height at the beginning of flowering, height of the first bunch and the number of inflorescences, bunch per plant and capsules per bunch. There is an increased sample size (number of plants) to determine the characters of seed, seedling, plant and production, in that order.

Key words: Ricinus communis L., experimental planning, sample dimensioning, experimental precision.

\section{INTRODUÇÃO}

Avaliações de diversos caracteres, em experimentos nas mais diferentes áreas, são comuns e importantes para o aproveitamento dos recursos investidos e maximização de informações. Especificamente, em experimentos agrícolas, a mensuração em todas as plantas (indivíduos) da área útil da unidade experimental é adequada para estimar o caractere em avaliação. No entanto, é comum a medição de uma parte das plantas da unidade experimental (amostra) para minimizar: mão-de-obra, tempo e recursos financeiros e humanos, devendo a amostra ser representativa das plantas da unidade experimental (STEEL et al., 1997).

O tamanho de amostra é diretamente proporcional à variabilidade dos dados e ao grau de confiança desejado na estimativa e inversamente proporcional ao erro de estimação permitido, fixado $a$

IDepartamento de Fitotecnia, Centro de Ciências Rurais (CCR), Universidade Federal de Santa Maria (UFSM), 97105-900, Santa

Maria, RS, Brasil. E-mail: cargnelutti@pq.cnpq.br. *Autor para correspondência.

IIPrograma de Pós-graduação em Agronomia, UFSM, Santa Maria, RS, Brasil.

${ }^{\text {IIIC } C u r s o ~ d e ~ A g r o n o m i a, ~ U F S M, ~ S a n t a ~ M a r i a, ~ R S, ~ B r a s i l . ~}$ 
priori pelo pesquisador. Assim, o dimensionamento do tamanho de amostra é importante para obtenção de estimativas com a precisão desejada.

Em caracteres de semente, de plântula, de planta adulta e de produção de híbridos de mamoneira (Ricinus communis L.), o tamanho de amostra não é conhecido. Em caso de homogeneidade de variâncias entre híbridos, estimativas com mesma precisão são obtidas a partir de tamanho de amostra único. No entanto, em presença de heterogeneidade de variâncias entre os híbridos, as estimativas obtidas com base em um mesmo tamanho de amostra apresentam precisão diferenciada. Assim, para obtenção de estimativas com a mesma precisão, há necessidade de estimar tamanho de amostra específico para diferentes caracteres de cada híbrido.

Existem variações entre as plantas de mamona em relação ao hábito de crescimento, à cor da folhagem e do caule, ao tamanho das sementes, ao conteúdo de óleo e ao porte da planta, tornando-se uma planta perene quando favorecida pelo ambiente (WEISS, 1983). A altura das plantas de mamona, por exemplo, é uma variável muito influenciada pelo ambiente, pois cultivares com altura média de $2 \mathrm{~m}$ no Nordeste brasileiro, quando cultivadas em outras regiões do país, podem atingir até $4 \mathrm{~m}$ (NÓBREGA, 2008).

Os híbridos Sara e Lyra apresentam características morfológicas e arquitetura de plantas diferenciadas. O híbrido Sara tem como características principais: arquitetura de planta mais aberta, maior quantidade de ramos produtivos, maior altura de plantas e rácemos menos compactos, enquanto que o híbrido Lyra apresenta arquitetura de planta mais fechada e menor quantidade de ramos produtivos, com rácemos maiores e mais compactos (BRUM, 2009).

A variabilidade entre os caracteres agronômicos dos híbridos de mamoneira e a influência do ambiente sobre esses híbridos sugerem distintos tamanhos de amostra. O objetivo deste trabalho foi estimar o tamanho de amostra para avaliar caracteres de híbridos de mamoneira e verificar a variabilidade do tamanho de amostra entre híbridos e caracteres.

\section{MATERIAL E MÉTODOS}

Dois híbridos de mamoneira (Sara e Lyra) foram avaliados em um experimento conduzido na Universidade Federal de Santa Maria, Santa Maria, Rio Grande do Sul (latitude 2942'S, longitude 53⒋' W e $95 \mathrm{~m}$ de altitude), no ano agrícola 2007/2008. Foram avaliadas, individualmente, 90 sementes do híbrido Sara e 90 sementes do híbrido Lyra quanto aos caracteres de semente (Tabela 1). As sementes foram identificadas com números de um a 180 e semeadas na área experimental, em 19 de outubro de 2007, conforme a recomendação para o cultivo da mamoneira no Rio Grande do Sul (WREGE et al., 2007), juntamente com as demais sementes que compuseram as seis parcelas (três parcelas do híbrido Sara e três parcelas do híbrido Lyra) de $15 \mathrm{~m}$ de comprimento $\mathrm{x} 16 \mathrm{~m}$ de largura. $\mathrm{O}$ espaçamento foi de $0,6 \mathrm{~m}$ entre plantas e $1,2 \mathrm{~m}$ entre linhas. Posteriormente, entre as sementes identificadas, emergiram 41 e 55 plantas dos híbridos Sara e Lyra, respectivamente, as quais foram avaliadas individualmente quanto aos caracteres de plântula, de planta adulta e de produção (Tabelas 1 e 2).

Os dados de temperaturas máxima e mínima do ar, para o cálculo dos graus-dia, foram obtidos na estação meteorológica localizada a aproximadamente $30 \mathrm{~m}$ da área experimental. O cálculo da soma térmica, em graus-dia (GD), foi obtido por meio da expressão

$$
\mathrm{GD}=\sum_{\mathrm{i}=1}^{\mathrm{n}}\left(\frac{\operatorname{Tmáx}_{\mathrm{i}}+\operatorname{Tmín}_{\mathrm{i}}}{2}-\mathrm{T}_{\mathrm{b}}\right) \text {, na qual Tmáx e }
$$

Tmín são, respectivamente, temperaturas máxima e mínima do dia 1 até n-ésimo dia, e $\mathrm{T}_{\mathrm{b}}$ é a temperatura basal da cultura, de $10^{\circ} \mathrm{C}$.

Tomando-se por base as 41 e 55 plantas dos híbridos Sara e Lyra, respectivamente, calculou-se a média $(\mathrm{m})$, a variância $\left(\mathrm{s}^{2}\right)$ e o coeficiente de variação (CV) para cada um dos caracteres avaliados. Em cada caractere, aplicaram-se os testes t (bilateral) e F (bilateral), a 5\% de probabilidade de erro, para testar, respectivamente, a hipótese de igualdade entre as médias e homogeneidade entre as variâncias dos híbridos Sara e Lyra.

Para cada caractere e híbrido, calculou-se o tamanho de amostra $(\eta)$ para uma semiamplitude do intervalo de confiança (erro de estimação) igual a 2, 4, 6 e $8 \%$ da estimativa da média $(\mathrm{m})$, com coeficiente de confiança $(1-\alpha)$ de $95 \%$, por meio da expressão

$$
\eta=\frac{\mathrm{t}_{\alpha / 2}^{2} \mathrm{~s}^{2}}{(\text { erro de estimação })^{2}}
$$

(BARBETTA et al., 2004; BUSSAB \& MORETTIN, 2004; SPIEGEL et al., 2004), na qual $t_{\alpha / 2}$ é o valor crítico da distribuição $t$ de Student, cuja área à direita é igual a $\alpha / 2$, isto é, o valor de $t$, tal que $\mathrm{P}\left(\mathrm{t}>\mathrm{t}_{\alpha, 2}\right)=\alpha / 2$, com (n-1) graus de liberdade, $\operatorname{com} \alpha=5 \%$ de probabilidade de erro, e s $\mathrm{s}^{2}$ é a estimativa de variância.

A partir da expressão utilizada para o cálculo do tamanho de amostra, fixou-se $\eta$ em 41 e 55 plantas para os híbridos Sara e Lyra, respectivamente, e calculou-se o erro de estimação em percentagem da estimativa da média (m) para cada um dos caracteres, por meio da expressão

$$
\text { erro de estimação }=100 \frac{t_{\alpha / 2} s}{\sqrt{\eta} \mathrm{m}},
$$


Tabela 1 - Sigla, unidade e forma de coleta de caracteres de semente, de plântula e de planta adulta de híbridos de mamoneira (Ricinus communis L.)

\begin{tabular}{|c|c|c|c|}
\hline Caractere & Sigla & Unidade & Forma de coleta \\
\hline Peso & PESO & $\mathrm{g}$ & Pesagem individual realizada em balança analítica de precisão de $0,001 \mathrm{~g}$. \\
\hline Comprimento & COMP & $\mathrm{mm}$ & $\begin{array}{l}\text { Medido com paquímetro digital da carúncula até a outra extremidade da } \\
\text { semente, no sentido da rafe. }\end{array}$ \\
\hline Largura & LARG & $\mathrm{mm}$ & $\begin{array}{l}\text { Medida com paquímetro digital na parte central da semente, perpendicular à } \\
\text { medida do comprimento. }\end{array}$ \\
\hline Área & AREA & $\mathrm{mm}^{2}$ & Comprimento $\mathrm{x}$ largura \\
\hline Espessura & ESPE & $\mathrm{mm}$ & Medida com paquímetro digital na região mediana da semente. \\
\hline Dias para a emergência & DIAE & dias & Número de dias da semeadura até o aparecimento da plântula sobre o solo. \\
\hline Graus-dia para a emergência & GDE & ${ }^{\circ} \mathrm{C}$ dia & Graus-dia da semeadura até o aparecimento da plântula sobre o solo. \\
\hline $\begin{array}{l}\text { Comprimento do hipocótilo aos } \\
\text { sete dias após a emergência (DAE) }\end{array}$ & $\mathrm{CH} 7$ & $\mathrm{~cm}$ & Distância entre o nível do solo e a inserção dos cotilédones. \\
\hline $\begin{array}{l}\text { Comprimento do hipocótilo aos } 14 \\
\text { DAE }\end{array}$ & $\mathrm{CH} 14$ & $\mathrm{~cm}$ & Distância entre o nível do solo e a inserção dos cotilédones. \\
\hline $\begin{array}{l}\text { Comprimento do epicótilo aos } 14 \\
\text { DAE }\end{array}$ & CE14 & $\mathrm{cm}$ & Distância entre a inserção dos cotilédones até o ponto de crescimento. \\
\hline $\begin{array}{l}\text { DAE para emissão da primeira } \\
\text { folha verdadeira }\end{array}$ & DIAPF & dias & Número de dias da emergência até o aparecimento da $1^{\text {a }}$ folha verdadeira. \\
\hline $\begin{array}{l}\text { Graus-dia para emissão da } \\
\text { primeira folha verdadeira }\end{array}$ & GDPF & ${ }^{\circ} \mathrm{C}$ dia & Graus-dia da emergência até o aparecimento da $1^{\text {a }}$ folha verdadeira. \\
\hline Índice SPAD aos sete DAE & SPAD7 & - & $\begin{array}{l}\text { Medida direta com clorofilômetro. Média de três medidas realizada em três } \\
\text { pontos da plântula. }\end{array}$ \\
\hline Índice SPAD aos $14 \mathrm{DAE}$ & SPAD14 & - & $\begin{array}{l}\text { Medida direta com clorofilômetro. Média de três medidas realizada em três } \\
\text { pontos da plântula. }\end{array}$ \\
\hline Dias para o florescimento & DIAF & dias & Número de dias da semeadura até o aparecimento da primeira inflorescência. \\
\hline Graus-dia para o florescimento & GDF & ${ }^{\circ} \mathrm{C}$ dia & Graus-dia da semeadura até o aparecimento da primeira inflorescência. \\
\hline $\begin{array}{l}\text { Altura de planta no início do } \\
\text { florescimento }\end{array}$ & AP & $\mathrm{cm}$ & $\begin{array}{l}\text { No aparecimento da } 1^{\mathrm{a}} \text { inflorescência. Altura correspondente à distância entre } \\
\text { o nível do solo e a extremidade da haste principal. }\end{array}$ \\
\hline $\begin{array}{l}\text { Comprimento do caule com folhas } \\
\text { verdadeiras }\end{array}$ & $\mathrm{CC}$ & $\mathrm{cm}$ & $\begin{array}{l}\text { No aparecimento da } 1^{\text {a }} \text { inflorescência. Medida da distância entre a inserção } \\
\text { da } 1^{\underline{a}} \text { folha verdadeira e a inserção da última folha verdadeira. }\end{array}$ \\
\hline Diâmetro do caule a $10 \mathrm{~cm}$ do solo & $\mathrm{DC}$ & $\mathrm{cm}$ & $\begin{array}{l}\text { No aparecimento da } 1^{\text {a }} \text { inflorescência, mediu-se com paquímetro digital o } \\
\text { diâmetro do caule a } 10 \mathrm{~cm} \text { do solo. }\end{array}$ \\
\hline
\end{tabular}

Ciência Rural, v.40, n.2, fev, 2010. 
Tabela 2 - Sigla, unidade e forma de coleta de caracteres de planta adulta e de produção, de híbridos de mamoneira (Ricinus communis L.).

\begin{tabular}{|c|c|c|c|}
\hline Caractere & Sigla & Unidade & Forma de coleta \\
\hline Número de folhas & NF & - Caracte & 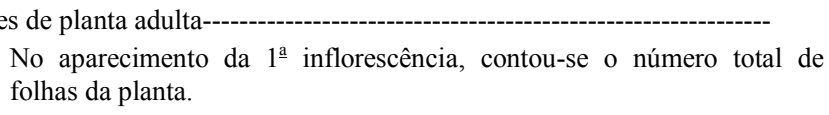 \\
\hline $\begin{array}{l}\text { Área Foliar média - método } \\
\text { comprimento e largura }\end{array}$ & AFCL & $\mathrm{cm}^{2}$ & $\begin{array}{l}\text { No aparecimento da } 1^{\text {a }} \text { inflorescência, mediu-se o máximo comprimento } \\
\text { e largura da folha. }\end{array}$ \\
\hline $\begin{array}{l}\text { Área Foliar média - método } \\
\text { comprimento da nervura principal }\end{array}$ & $\mathrm{AFCN}$ & $\mathrm{cm}^{2}$ & No aparecimento da $1^{\text {a }}$ inflorescência. \\
\hline $\begin{array}{l}\text { Altura de inserção do primeiro } \\
\text { rácemo }\end{array}$ & APR & $\mathrm{Cm}$ & 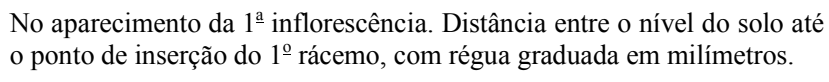 \\
\hline $\begin{array}{l}\text { Dias para o fim do florescimento a } \\
\text { partir da emergência }\end{array}$ & DFFE & Dias & Número de dias da emergência até a emissão da última inflorescência. \\
\hline $\begin{array}{l}\text { Dias para o fim do florescimento a } \\
\text { partir da semeadura }\end{array}$ & DFFS & Dias & Número de dias da semeadura até a emissão da última inflorescência. \\
\hline Altura do rácemo mais alto & $\mathrm{AR}$ & $\mathrm{Cm}$ & $\begin{array}{l}\text { No fim do florescimento. Distância entre o nível do solo e a extremidade } \\
\text { do rácemo mais alto da planta. }\end{array}$ \\
\hline $\begin{array}{l}\text { Graus-dia para o fim do } \\
\text { florescimento }\end{array}$ & GDFF & ${ }^{\circ} \mathrm{C}$ dia & Graus-dia da semeadura até a emissão da última inflorescência. \\
\hline Número de inflorescências & NI & & Contagem realizada na emissão da última inflorescência. \\
\hline $\begin{array}{l}\text { Comprimento médio dos rácemos } \\
\text { por planta }\end{array}$ & CRP & $\mathrm{Cm}$ & $\begin{array}{l}\text { Após a colheita, foi medido o comprimento do rácemo com presença de } \\
\text { cápsulas, em todos os rácemos da planta e obteve-se a média. }\end{array}$ \\
\hline Número de rácemos por planta & NRP & - & Contagem realizada no momento da colheita. \\
\hline $\begin{array}{l}\text { Número médio de cápsulas por } \\
\text { rácemo }\end{array}$ & NCR & - & $\begin{array}{l}\text { Após a colheita, contou-se o número de cápsulas em todos os cachos da } \\
\text { planta, para obtenção do número médio de cápsulas por rácemo por } \\
\text { planta. }\end{array}$ \\
\hline Peso médio de cápsulas por racemo & PCR & $\mathrm{g}$ & $\begin{array}{l}\text { Após a colheita e retirada das cápsulas, pesaram-se as cápsulas de cada } \\
\text { planta para obtenção da média em balança analítica de precisão de } \\
0,0001 \mathrm{~g} \text {. }\end{array}$ \\
\hline Peso total de cápsula por planta & PCP & g & $\begin{array}{l}\text { Após a colheita e retirada das cápsulas, pesaram-se todas as cápsulas de } \\
\text { cada planta em balança analítica de precisão de } 0,0001 \mathrm{~g} \text {. }\end{array}$ \\
\hline Peso médio de grãos por racemo & PGR & g & $\begin{array}{l}\text { Após a debulha das cápsulas, os grãos de todos os rácemos da planta } \\
\text { foram pesados em balança analítica de precisão de } 0,0001 \mathrm{~g} \text {. }\end{array}$ \\
\hline Produtividade de grãos por planta & PGP & g & $\begin{array}{l}\text { Após a debulha das cápsulas, foi pesada a produção de grãos por planta } \\
\text { em balança analítica de precisão de } 0,0001 \mathrm{~g} \text {. }\end{array}$ \\
\hline Epicarpo (casca) & EPI & g & $\begin{array}{l}\text { Obtida pela diferença entre o peso de cápsulas da planta e o peso de } \\
\text { grãos. }\end{array}$ \\
\hline Percentual de epicarpo (casca) & PEPI & $\%$ & $\begin{array}{l}\text { Percentual obtido pela relação entre o peso total de cápsulas da planta e } \\
\text { o peso de epicarpo (casca). }\end{array}$ \\
\hline Massa de cem grãos & MASSA & G & $\begin{array}{l}\text { Média obtida pela pesagem de duas repetições de } 100 \text { sementes de cada } \\
\text { planta em balança analítica de precisão de } 0,0001 \mathrm{~g} \text {. Umidade de } 9 \% \text {. }\end{array}$ \\
\hline
\end{tabular}

Ciência Rural, v.40, n.2, fev, 2010. 
em que s é a estimativa do desvio padrão. As análises estatísticas foram realizadas com o auxílio do programa GENES (CRUZ, 2006) e do aplicativo Office Excel.

\section{RESULTADOS E DISCUSSÃO}

Pelo teste $t$, não houve diferença significativa entre os híbridos de mamoneira (Sara e Lyra) quanto aos caracteres relacionados à semente. No entanto, nos demais 33 caracteres relacionados à plântula, à planta adulta e à produção, a presença de variabilidade genética foi constatada entre os dois híbridos em 25 caracteres avaliados, o que evidencia híbridos contrastantes (Tabela 3).

As variâncias entre os híbridos de mamoneira (Sara e Lyra) foram heterogêneas em oito caracteres: largura da semente, comprimento do epicótilo aos 14 dias após a emergência, graus-dia para emissão da primeira folha verdadeira, altura de planta no início do florescimento, altura de inserção do primeiro rácemo e número de inflorescências, de rácemos por planta e de cápsulas por rácemo, o que indica tamanho de amostra diferenciado entre os híbridos (Tabela 3). Nos demais 30 caracteres $(79 \%$ dos caracteres), as variâncias foram homogêneas, o que mostra que o tamanho de amostra pode ser o mesmo para os dois híbridos estudados, ou seja, poderia ser utilizado o tamanho de amostra médio. De maneira geral, a influência do ambiente tem sido destacada como causa de variabilidade em caracteres de híbridos de mamoneira (WEISS, 1983; KOUTROUBAS et al., 1999; FIGUEIREDO NETO et al., 2004).

Entre os 38 caracteres do híbrido Sara, o coeficiente de variação oscilou entre 3,91 (largura da semente) e $67,37 \%$ (área foliar média por meio do método do comprimento da nervura principal). Já em relação ao híbrido Lyra, o coeficiente de variação variou entre 4,55 (espessura da semente) e 79,53\% (número de rácemos por planta) (Tabela 3). A média dos coeficientes de variação dos híbridos Sara e Lyra foi de 7,76, 17,98, 24,49 e $39,31 \%$, respectivamente, para os caracteres de semente, de plântula, de planta adulta e de produção, sugerindo que o tamanho de amostra deve ser proporcional a esse aumento de variabilidade, para obtenção de estimativas com uma mesma precisão. Por outro lado, estimativas obtidas a partir de um tamanho de amostra único apresentariam um decréscimo de precisão para os caracteres de semente, de plântula, de planta adulta e de produção, nessa ordem. Esse aumento na variabilidade entre plantas é, provavelmente, explicado pelo maior tempo de permanência das plantas no campo sob os efeitos ambientais.
Em trabalho com 10 genótipos de mamoneira, cinco de porte alto e cinco de porte baixo, NÓBREGA (2008) observou valores de coeficiente de variação entre 4,04 e 28,5\% para os caracteres potencial produtivo, peso de 100 sementes, dias para o florescimento, altura média da planta, altura do caule, diâmetro do caule, comprimento total do rácemo primário, comprimento efetivo do rácemo primário, número de nós do caule e comprimento dos internós, sendo o rendimento o caractere com maior coeficiente de variação $(28,5 \%)$. O autor salienta que, na maioria das culturas, os coeficientes de variação para caracteres produtivos são elevados, em razão da grande influência ambiental.

O tamanho de amostra, para a estimativa da média de cada caractere em cada híbrido, com semiamplitude do intervalo de confiança igual a $2 \%$ da estimativa da média (m) e coeficiente de confiança de $95 \%$, oscilou de 18 plantas, para os caracteres largura e espessura de semente do híbrido Sara, a 6.077 plantas, para o número de inflorescências e de rácemos do híbrido Lyra (Tabela 4). Portanto, em relação aos caracteres largura e espessura de semente do híbrido Sara, pode-se inferir, com $95 \%$ de confiança, que o intervalo de confiança da média $(\mu)$ desses caracteres, obtida com 18 plantas, é de $\mu \pm 0,02 \mathrm{~m}$. Em outro extremo, a precisão de $\mu \pm 0,02$ mé obtida com 6.077 plantas, para o número de inflorescências e de rácemos do híbrido Lyra. Esses resultados confirmam a variabilidade existente entre híbridos e caracteres. Portanto, observações em 6.077 plantas forneceriam estimativas de média desses híbridos e caracteres, com 95\% de confiabilidade de que o erro máximo é $0,02 \mathrm{~m}$. Variabilidade de tamanho de amostra entre genótipos, caracteres e experimentos foi constatada em feijão (CARGNELUTTI FILHO et al., 2008) e em soja (CARGNELUTTI FILHO et al., 2009).

Do ponto de vista prático, a avaliação em 6.077 plantas é difícil. Assim, menores tamanhos de amostra foram estimados com base em semiamplitudes do intervalo de confiança igual a 4, 6 e $8 \%$ de $m$ (Tabela 4). Não cabe aqui o julgamento do erro de estimação máximo aceitável, ficando isso a critério do pesquisador que usufruir dessas informações para o seu planejamento experimental. Portanto, tomando-se como referência o maior tamanho de amostra (número de inflorescências e de rácemos do híbrido Lyra), pode-se inferir, com 95\% de confiança, que, com o uso de 383 observações (plantas), o erro máximo na estimativa da média será de $\pm 8 \%$ de $\mathrm{m}$. Ainda assim, a avaliação de 383 plantas é onerosa, o que sugere que as estimativas desses caracteres sejam obtidas com menor número de plantas e com erro de estimação maior que $8 \%$ de $\mathrm{m}$. 
Tabela 3 - Média, variância e coeficiente de variação (CV) de caracteres de dois híbridos de mamoneira (Ricinus communis L.), respectivamente, dos híbridos Sara e Lyra e resultados do teste t para comparação de médias e teste $\mathrm{F}$ para comparação de variâncias.

\begin{tabular}{|c|c|c|c|c|c|c|c|c|}
\hline \multirow{2}{*}{ Caractere $^{(1)}$} & \multicolumn{3}{|c|}{ 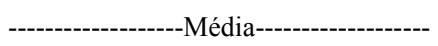 } & \multicolumn{3}{|c|}{------------------Variância------------------- } & \multicolumn{2}{|c|}{ 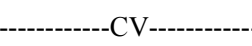 } \\
\hline & Sara & Lyra & Teste $\mathrm{t}$ & Sara & Lyra & Teste $\mathrm{F}$ & Sara & Lyra \\
\hline PESO & 0,44 & 0.43 & $\mathrm{~ns}$ & $\begin{array}{l}\text { eteres de seme } \\
0,004\end{array}$ & 0,005 & Homogêneas & 14.15 & 16,74 \\
\hline COMP & 13,50 & 13,56 & ns & 0,495 & 0,530 & Homogêneas & 5,21 & 5,37 \\
\hline LARG & 9,55 & 9,55 & $\mathrm{~ns}$ & 0,140 & 0,260 & Heterogêneas & 3,91 & 5,35 \\
\hline AREA & 129,10 & 129,70 & ns & 113,144 & 174,441 & Homogêneas & 8,24 & 10,18 \\
\hline ESPE & 6,56 & 6,56 & ns & 0,066 & 0,089 & Homogêneas & 3,93 & 4,55 \\
\hline DIAE & 9,98 & 11,11 & * & 7,024 & 5,210 & Homogêneas & 26,57 & 20,55 \\
\hline GDE & 134,43 & 146,02 & * & 594,154 & 422,743 & Homogêneas & 18,13 & 14,08 \\
\hline $\mathrm{CH} 7$ & 5,94 & 4,55 & $*$ & 1,184 & 0,819 & Homogêneas & 18,33 & 19,91 \\
\hline CH14 & 6,94 & 5,36 & * & 2,017 & 1,469 & Homogêneas & 20,45 & 22,61 \\
\hline CE14 & 3,21 & 2,06 & $*$ & 0,803 & 0,235 & Heterogêneas & 27,93 & 23,53 \\
\hline DIAPF & 4,37 & 4,38 & ns & 0,988 & 1,018 & Homogêneas & 22,76 & 23,03 \\
\hline GDPF & 179,25 & 187,06 & $*$ & 483,805 & 268,178 & Heterogêneas & 12,27 & 8,75 \\
\hline SPAD7 & 42,03 & 46,66 & $*$ & 19,957 & 30,952 & Homogêneas & 10,63 & 11,92 \\
\hline SPAD14 & 46,93 & 50,40 & * & 31,696 & 26,210 & Homogêneas & 12,00 & 10,16 \\
\hline DIAF & 40,17 & 48,76 & $*$ & 23,295 & 36,999 & Homogêneas & 12,01 & 12,47 \\
\hline GDF & 464,73 & 578,94 & $*$ & 3926,799 & 6554,385 & Homogêneas & 13,48 & 13,98 \\
\hline $\mathrm{AP}$ & 26,62 & 25,95 & ns & 38,774 & 17,441 & Heterogêneas & 23,39 & 16,10 \\
\hline $\mathrm{CC}$ & 15,79 & 18,21 & $*$ & 16,915 & 13,044 & Homogêneas & 26,05 & 19,84 \\
\hline DC & 12,37 & 19,85 & $*$ & 7,462 & 9,231 & Homogêneas & 22,07 & 15,30 \\
\hline $\mathrm{NF}$ & 8,07 & 9,31 & $*$ & 1,470 & 1,255 & Homogêneas & 15,02 & 12,03 \\
\hline AFCL & 248,83 & 445,61 & $*$ & 18713,075 & 14588,316 & Homogêneas & 54,97 & 27,10 \\
\hline $\mathrm{AFCN}$ & 178,05 & 358,10 & * & 14387,074 & 13145,353 & Homogêneas & 67,37 & 32,02 \\
\hline APR & 26,62 & 25,95 & $\mathrm{~ns}$ & 38,774 & 17,441 & Heterogêneas & 23,39 & 16,10 \\
\hline DFFE & 87,54 & 98,73 & * & 266,255 & 195,202 & Homogêneas & 18,64 & 14,15 \\
\hline DFFS & 96,96 & 109,19 & $*$ & 207,355 & 167,670 & Homogêneas & 14,85 & 11,86 \\
\hline $\mathrm{AR}$ & 172,71 & 135,07 & $*$ & 597,875 & 551,642 & Homogêneas & 14,16 & 17,39 \\
\hline GDFF & 1475,36 & 1629,35 & $*$ & 45811,750 & 36034,089 & Homogêneas & 14,51 & 11,65 \\
\hline NI & 25,75 & 10,31 & * & 291,140 & 67,201 & Heterogêneas & 66,27 & 79,53 \\
\hline CRP & 18,57 & 31,28 & $*$ & 65,837 & 85,406 & Homogêneas & 43,69 & 29,54 \\
\hline NRP & 22,39 & 8,96 & * & 220,144 & 50,813 & Heterogêneas & 66,27 & 79,53 \\
\hline NCR & 20,28 & 40,10 & $*$ & 20,145 & 150,338 & Heterogêneas & 22,13 & 30,57 \\
\hline PCR & 69,53 & 79,69 & ns & 561,408 & 949,749 & Homogêneas & 34,08 & 38,67 \\
\hline PCP & 723,20 & 656,93 & $\mathrm{~ns}$ & 118656,360 & 88899,248 & Homogêneas & 47,63 & 45,39 \\
\hline PGR & 53,97 & 65,79 & $*$ & 598,461 & 819,346 & Homogêneas & 45,33 & 43,51 \\
\hline PGP & 510,41 & 464,71 & ns & 64709,541 & 43826,219 & Homogêneas & 49,84 & 45,05 \\
\hline EPI & 219,71 & 192,98 & ns & 15050,004 & 10551,409 & Homogêneas & 55,84 & 53,23 \\
\hline PEPI & 29,29 & 28,81 & $\mathrm{~ns}$ & 26,522 & 32,657 & Homogêneas & 17,58 & 19,83 \\
\hline MASSA & 46,89 & 51,20 & * & 22,313 & 18,251 & Homogêneas & 10,07 & 8,34 \\
\hline
\end{tabular}

(1) Siglas definidas nas tabelas 1 e $2 . *$ Médias de híbridos diferem, pelo teste t bilateral, a $5 \%$ de probabilidade de erro. ${ }^{\text {ns }}$ Não significativo. Heterogêneas: variâncias heterogêneas pelo teste $\mathrm{F}$ bilateral, a 5\% de probabilidade de erro. Homogêneas: variâncias homogêneas.

Para exemplicar, caso a opção seja amostrar 41 e 55 plantas, respectivamente, para os híbridos Sara e Lyra, o erro de estimação seria, respectivamente, de: $\pm 20,92 \%$ de $\mathrm{m}$ e de $\pm 21,50 \%$ de $\mathrm{m}$ (Tabela 4 ).
O tamanho de amostra médio dos híbridos Sara e Lyra, com semiamplitude do intervalo de confiança igual a $8 \%$ de m e coeficiente de confiança de $95 \%$, foi de 6, 25, 59 e 115 plantas, respectivamente, 
Tabela 4 - Tamanho de amostra (número de plantas) de caracteres de dois híbridos de mamoneira (Ricinus communis L.), para uma semiamplitude do intervalo com $95 \%$ de confiança igual a $2,4,6$ e $8 \%$ da média e semiamplitude do intervalo de confiança em percentagem da estimativa da média (m) do caractere (Erro \%), com base em 41 e 55 plantas, respectivamente, dos híbridos Sara e Lyra.

\begin{tabular}{|c|c|c|c|c|c|c|c|c|c|c|}
\hline \multirow{2}{*}{ Caractere $^{(1)}$} & \multicolumn{6}{|c|}{ 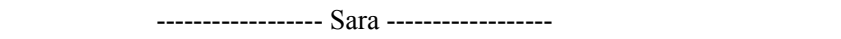 } & \multicolumn{4}{|c|}{---------------- Lyra ----------------- } \\
\hline & $2 \%$ & $4 \%$ & $6 \%$ & $8 \%$ & Erro \% & $2 \%$ & $4 \%$ & $6 \%$ & $8 \%$ & Erro \% \\
\hline \multicolumn{11}{|c|}{--------------------------------------- Caracteres de semente ------------------------------------- } \\
\hline PESO & 195 & 51 & 24 & 15 & 4,47 & 272 & 70 & 33 & 20 & 4,53 \\
\hline COMP & 29 & 10 & 6 & 2 & 1,64 & 31 & 10 & 7 & 2 & 1,45 \\
\hline LARG & 18 & 7 & 2 & 1 & 1,24 & 30 & 10 & 5 & 2 & 1,45 \\
\hline AREA & 68 & 19 & 10 & 8 & 2,60 & 102 & 28 & 14 & 9 & 2,75 \\
\hline ESPE & 18 & 7 & 2 & 1 & 1,24 & 23 & 8 & 3 & 2 & 1,23 \\
\hline \multicolumn{11}{|c|}{ 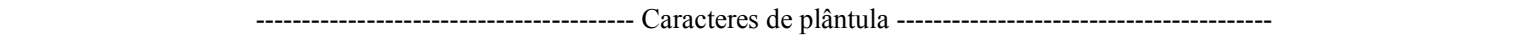 } \\
\hline DIAE & 681 & 172 & 78 & 45 & 8,39 & 408 & 104 & 48 & 28 & 5,55 \\
\hline GDE & 319 & 82 & 38 & 23 & 5,72 & 193 & 51 & 24 & 15 & 3,81 \\
\hline $\mathrm{CH} 7$ & 326 & 84 & 39 & 23 & 5,79 & 384 & 98 & 45 & 27 & 5,38 \\
\hline CH14 & 405 & 103 & 48 & 28 & 6,46 & 494 & 126 & 57 & 34 & 6,11 \\
\hline CE14 & 752 & 190 & 86 & 50 & 8,82 & 535 & 136 & 62 & 36 & 6,36 \\
\hline DIAPF & 501 & 127 & 58 & 34 & 7,19 & 512 & 130 & 59 & 35 & 6,23 \\
\hline GDPF & 148 & 39 & 19 & 12 & 3,87 & 77 & 21 & 11 & 8 & 2,37 \\
\hline SPAD7 & 111 & 30 & 15 & 10 & 3,36 & 139 & 37 & 18 & 12 & 3,22 \\
\hline SPAD14 & 141 & 37 & 18 & 12 & 3,79 & 102 & 28 & 14 & 9 & 2,75 \\
\hline \multicolumn{11}{|c|}{ 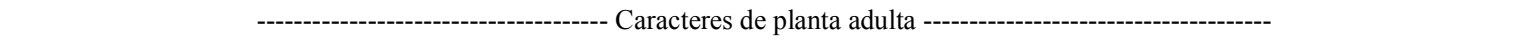 } \\
\hline DIAF & 142 & 38 & 18 & 12 & 3,79 & 152 & 40 & 20 & 12 & 3,37 \\
\hline GDF & 178 & 47 & 22 & 14 & 4,26 & 191 & 50 & 24 & 15 & 3,78 \\
\hline $\mathrm{AP}$ & 528 & 134 & 61 & 36 & 7,38 & 252 & 65 & 31 & 19 & 4,35 \\
\hline $\mathrm{CC}$ & 655 & 166 & 75 & 44 & 8,22 & 381 & 97 & 45 & 27 & 5,36 \\
\hline $\mathrm{DC}$ & 471 & 120 & 55 & 32 & 6,97 & 228 & 59 & 28 & 17 & 4,14 \\
\hline $\mathrm{NF}$ & 219 & 57 & 27 & 17 & 4,74 & 142 & 38 & 18 & 12 & 3,25 \\
\hline AFCL & 2905 & 729 & 325 & 184 & 17,35 & 708 & 179 & 81 & 47 & 7,33 \\
\hline $\mathrm{AFCN}$ & 4362 & 1093 & 487 & 275 & 21,26 & 987 & 249 & 112 & 64 & 8,66 \\
\hline APR & 528 & 134 & 61 & 36 & 7,38 & 252 & 65 & 31 & 19 & 4,35 \\
\hline DFFE & 337 & 86 & 40 & 24 & 5,88 & 195 & 51 & 24 & 15 & 3,83 \\
\hline DFFS & 215 & 56 & 26 & 16 & 4,69 & 138 & 37 & 18 & 11 & 3,21 \\
\hline AR & 195 & 51 & 24 & 15 & 4,47 & 293 & 75 & 35 & 21 & 4,70 \\
\hline GDFF & 205 & 53 & 25 & 16 & 4,58 & 133 & 36 & 17 & 11 & 3,15 \\
\hline NI & 4220 & 1057 & 471 & 266 & 20,92 & 6077 & 1521 & 678 & 383 & 21,50 \\
\hline \multicolumn{11}{|c|}{ 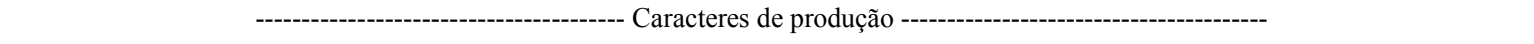 } \\
\hline CRP & 1836 & 461 & 207 & 118 & 13,79 & 841 & 212 & 96 & 55 & 7,99 \\
\hline NRP & 4220 & 1057 & 471 & 266 & 20,92 & 6077 & 1521 & 678 & 383 & 21,50 \\
\hline NCR & 473 & 120 & 55 & 32 & 6,99 & 901 & 227 & 103 & 59 & 8,27 \\
\hline PCR & 1118 & 282 & 127 & 73 & 10,76 & 1439 & 362 & 163 & 93 & 10,45 \\
\hline PCP & 2182 & 548 & 245 & 139 & 15,03 & 1981 & 497 & 223 & 127 & 12,27 \\
\hline PGR & 1976 & 496 & 222 & 126 & 14,31 & 1821 & 457 & 205 & 117 & 11,76 \\
\hline PGP & 2388 & 599 & 268 & 152 & 15,73 & 1952 & 490 & 219 & 125 & 12,18 \\
\hline EPI & 2997 & 751 & 336 & 190 & 17,62 & 2724 & 683 & 305 & 173 & 14,39 \\
\hline PEPI & 300 & 77 & 36 & 22 & 5,55 & 381 & 97 & 45 & 27 & 5,36 \\
\hline MASSA & 100 & 27 & 14 & 9 & 3,18 & 70 & 20 & 10 & 7 & 2,26 \\
\hline
\end{tabular}

(1) Siglas definidas nas tabelas 1 e 2 .

adulta e de produção (Tabela 4). Isso revela a necessidade de maior tamanho de amostra em relação aos caracteres que permanecem por mais tempo sob tamanho de amostra é crescente na seguinte ordem: caracteres de semente, de plântula, de planta adulta e de produção.

Ciência Rural, v.40, n.2, fev, 2010. 
Os resultados evidenciam que, do ponto de vista de técnicas experimentais, os pesquisadores da cultura de mamoneira devem considerar o híbrido e os caracteres, ao dimensionar o tamanho de amostra para uma avaliação mais precisa. Poder-se-ia optar por um tamanho de amostra maior, para os caracteres que assim o exigem, reduzindo o tamanho para os demais caracteres.

\section{CONCLUSÕES}

Há variabilidade da estimativa do tamanho de amostra entre os híbridos de mamoneira Sara e Lyra, para os caracteres largura da semente, comprimento do epicótilo aos 14 dias após a emergência, graus-dia para emissão da primeira folha verdadeira, altura de planta no início do florescimento, altura de inserção do primeiro rácemo, número de inflorescências, número de rácemos por planta e número de cápsulas por rácemo.

Há aumento do tamanho de amostra (número de plantas) para estimar caracteres de semente, de plântula, de planta adulta e de produção, nessa ordem.

\section{AGRADECIMENTOS}

Ao Conselho Nacional de Desenvolvimento Científico e Tecnológico (CNPq), pela concessão de bolsas de Produtividade em Pesquisa e de Iniciação Científica.

\section{REFERÊNCIAS}

BARBETTA, P.A. et al. Estatística para cursos de engenharia e informática. São Paulo: Atlas, 2004. 410p.

BRUM, B. Relações entre variáveis de: sementes, plântulas, plantas, produção e óleo em mamoneira. 2009. 120f. Dissertação (Mestrado em Agronomia) - Curso de Pósgraduação em Agronomia, Universidade Federal de Santa Maria, RS.
BUSSAB, W.O.; MORETTIN, P.A. Estatística básica. 5.ed. São Paulo: Saraiva, 2004. 526p.

CARGNELUTTI FILHO, A. et al. Tamanho de amostra de caracteres de genótipos de soja. Ciência Rural, v.39, p.983991, 2009. Disponível em: <http://www.scielo.br/ s cielo.php? s cript=sci_arttext\&pid=S 0103 $84782009000400005 \& \operatorname{lng}=\mathrm{pt} \& \mathrm{nrm}=\mathrm{iso}>$. Acesso em: 10 set. 2009. doi: 10.1590/S0103-84782009005000016.

CARGNELUTTI FILHO, A. et al. Tamanho de amostra de caracteres de cultivares de feijão. Ciência Rural, v.38, p.635642, 2008. Disponível em: <http://www.scielo.br/ scielo.php? script=s ci_art text \& pid=S 0103 $84782008000300007 \& \operatorname{lng}=\mathrm{pt} \& \mathrm{nrm}=\mathrm{iso}>$. Acesso em: 10 set. 2009. doi: 10.1590/S0103-84782008000300007.

CRUZ, C.D. Programa genes: estatística experimental e matrizes. Viçosa: UFV, 2006. 285p.

FIGUEIREDO NETO, A. et al. Divergência genética em acessos de mamona (Ricinus communis L.) baseada nas características das sementes. Revista de Biologia e Ciência da Terra, v.4, p.1-10, 2004.

KOUTROUBAS, S.D. et al. Adaptation and yielding ability of castor plant (Ricinus communis L.) genotypes in a Mediterranean climate. European Journal of Agronomy, v.11, p.227-237, 1999.

NÓBREGA, M.B. de M. Avaliação de genótipos de mamona (Ricinus communis L.) em cruzamentos dialélicos parciais. 2008. 77f. Tese (Doutorado em Agronomia) - Escola Superior de Agricultura Luiz de Queiroz, Universidade de São Paulo, SP.

SPIEGEL, R.A. et al. Probabilidade e estatística. 2.ed. Porto Alegre: Bookman, 2004. 398p.

STEEL, R.G.D. et al. Principles and procedures of statistics a biometrical approach. 3.ed. Nova York: McGraw-Hill, 1997. 666p.

WEISS, E.A. Oilseed Crops. New York: Longman, 1983. $660 \mathrm{p}$.

WREGE, M.S. et al. Zoneamento agroclimático para mamona no Rio Grande do Sul. Pelotas: Embrapa Clima Temperado, 2007. 30p. (Embrapa Clima Temperado. Documentos, 192). 